\title{
Comparative study of Olopatadine $0.1 \%$ and Lodoxamide $0.1 \%$ in treatment of seasonal allergic conjunctivitis
}

\author{
Azzam A. Ahmed \\ Department of Surgery, College of Medicine, University of Mosul.
}

(Ann. Coll. Med. Mosul 2010; 36 (1 \& 2): 138-145).

Received: $30^{\text {th }}$ Sept 2009; Accepted: $19^{\text {th }}$ May 2010.

\begin{abstract}
Objective: Olopatadine hydrochloride $0.1 \%$ ophthalmic solution and Lodoxamide $0.1 \%$ ophthalmic solution are two topical anti-allergic medications with slightly different modes of action. This study compared the efficacy, tolerability and safety of these agents in the treatment of allergic conjunctivitis Methods: This was a three weeks prospective, randomized, double-masked, active-controlled, parallel group comparison study of Olopatadine hydrochloride $0.1 \%$ ophthalmic solution (Patanol) and Lodoxamide $0.1 \%$ (Alomide) in patients with seasonal allergic conjunctivitis. Subjects were dosed twice daily for three weeks with either Olopatadine or Lodoxamide. Signs and symptoms were assessed on day five (visit 2) and 21 (visit 3). Efficacy variables included the responder rate (patient with excellent or good global efficacy on day 5 and 21), signs and symptoms, and patient and investigator-rated global efficacy. Comfort was rated immediately after instillation of the first drop and at each follow-up visit. Frequency of adverse events was the safety assessment.

Results: The study enrolled 66 patients, and 63 patients completed the study. The responder rate was higher with Olopatadine than with Lodoxamide on both fifth day ( $72 \%$ vs $54 \%$ for patient assessment and $88 \%$ vs. $55 \%$ for investigator assessment), and day 21 (91\% vs. $55 \%$ for patient assessment and $94 \%$ vs. $42 \%$ for investigator assessment). Global efficacy ratings were higher for Olopatadine -treated subjects than Lodoxamide -treated patients. Severity scores for hyperemia and itching were significantly lower for Olopatadine-treated group. Comfort ratings were comparable between the two treatment groups. Common adverse events included burning/stinging and headache. Conclusion: Olopatadine hydrochloride was superior in treating the signs and symptoms of allergic conjunctivitis. Both treatments were safe and well tolerated.
\end{abstract}

الهـدف: تهدف هذه الدراسة التقييم ألسريري ومقارنة نتائج نوعين من قطر ات العيون التي تستعمل لعلاج حساسية العين

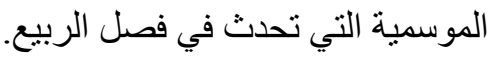
التصميم: در اسة مقطعية.

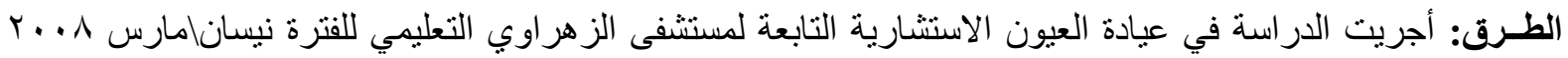

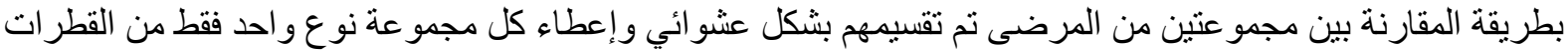

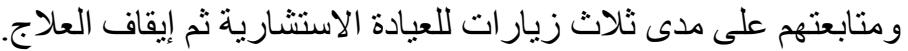

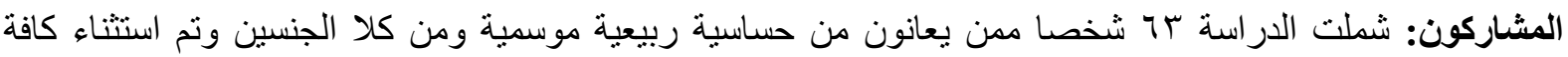

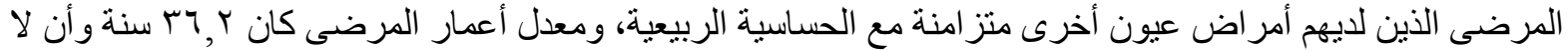

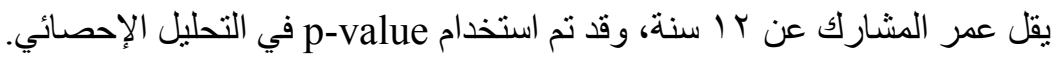

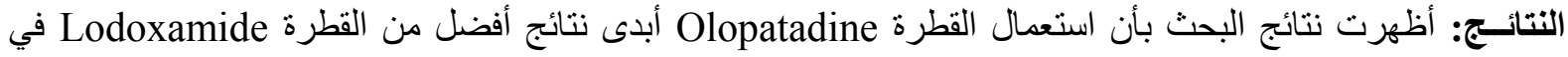
علاج حساسية العين الموسمية الربيعية. 
الاستنتاج: قطرة Olopatadine هي أفضل من قطرة Lodoxamide في علاج أعراض وعلامات حساسية العين، علما" أن كلتا القطرتين هما علاج آمن في علاج حساسية العين.

$\mathrm{S}$ easonal allergic conjunctivitis (SAC) is most prevalent during spring and late fall, it is the ocular component of hay fever and its occurrence usually coincides with peak pollen season ${ }^{(1)}$. The characteristic clinical manifestations of allergic conjunctivitis include ocular itching, redness, watery tearing, burning, foreign body sensation and eyelid edema. Although SAC is usually self limiting and does not threaten vision, it can cause great discomfort and aggravation. ${ }^{(1,2)}$

Allergic conjunctivitis is triggered by airborne allergens binding $\mathrm{IgE}$ antibodies fixed to conjunctival mast cells, which leads to mast cell degranulation and release of chemical mediators. These chemical mediators produce a biphasic response: an early-phase and a late-phase response. The early or acute phase begins upon allergen exposure and lasts 40 to 60 minutes. Histamine is the primary mediator of early phase, producing the itching and vasodilatation that are the hallmark of this condition ${ }^{(2)}$. Two types of histamine receptors: $\mathrm{H}_{1}$ and $\mathrm{H}_{2}$ have been identified in human conjunctiva. Stimulation of $\mathrm{H}_{1}$ receptors results in itching, whereas stimulation of $\mathrm{H}_{2}$ receptors elicits redness ${ }^{(2)}$. The late phase occurs 2 to 24 hours after antigen exposure and results from the infiltration and activation of inflammatory cells such as eosinophils and macrophages. The late phase propagates the allergic response and leads to a resurgence of ocular symptoms. ${ }^{(1,3)}$

Topical anti-allergic prescription medications have been the mainstay of therapy for allergic conjunctivitis. Optimally, drug therapy provides both immediate relief from symptoms of allergic manifestations as well as long-term control. To meet this goal, dual or multi-action drugs are now available that combine the immediate relief obtained from topical antihistamine and long-term control found with mast cell stabilizers. ${ }^{(3,4)}$

$(\mathrm{OH})$ is an anti-allergy agent with a separate and distinct multiple mechanisms of action (mast cell stabilizer, Histamine receptor antagonism and eosinophil inhibition) that can lead to powerful and sustained inhibition of allergic response. Lodoxamide is a widely used topical anti-allergy agent with dual activity- antihistaminic and mast-cell stabilizing actions. In this study, the efficacy, tolerability and safety of Olopatadine hydrochloride $0.1 \%$ ophthalmic solution and Lodoxamide $0.1 \%$ ophthalmic solution were compared during a three week treatment period in patients suffering from allergic conjunctivitis. The study was designed to reflect real-life conditions of allergic patients. ${ }^{(2-4)}$

\section{Methods}

\section{Study population}

This study was conducted at Al-Jumhory Teaching Hospital in the Ophthalmic Out patient Clinic during the spring allergy season between April-May 2008 which correlated with ragweed pollinosis.

Patients were of either sex, any race, at least 12 years of age, and suffering from seasonal allergic conjunctivitis with mild, moderate and severe signs and symptoms- defined by ocular itching score of at least $2+$ and seasonal allergic conjunctivitis symptomatology (Table 1). Patients were required to have a history of allergic conjunctivitis.

Patients with any other ocular condition other than allergic conjunctivitis were excluded from the study. Exclusion criteria include history of ocular herpes, retinal detachment, diabetic retinopathy, or any retinal disease or the presence of any ocular condition that could have affected trial variables (especially narrow angle glaucoma, bacterial, viral or follicular conjunctivitis; ocular herpes; iritis; preauricular lymphadenopathy; mucous discharge; excess lacrimation or the diagnosis of dry eye). Likewise, patients on any concomitant topical medications with potential to interfere with patient's response to therapy or any condition requiring concurrent treatment with topical $\mathrm{H}_{1}$ antihistamines, mast cell stabilizers, nonsteroidal anti-inflammatory drugs were 
excluded. Patients who had ocular surgery within two months of the study or had known hypersensitivity to any component of the study medications were also excluded from the study.

\section{Study design}

This was a single-center, randomized, double masked, parallel dosing design evaluation of the efficacy, safety and comfort of $(\mathrm{OH})$ versus (L).

The study involved a total of three visits over a three week period: a base line visit and two follow-up visits.

\section{Visit (1): qualification, baseline assessment and treatment assignment (day 0 )}

Eligible patients were evaluated for participation by queries of past and present medical history, current diagnosis and concomitant medications. An external eye examination was performed to evaluate the signs of allergic conjunctivitis (conjunctival hyperemia, conjunctival chemosis, eyelid swelling and mucous discharge). Patients subjectively evaluated their symptoms (itching and tearing). To be enrolled in the study, patients had to have an itching score of at least an intensity of 2 (mild continuous itch not requiring eye rubbing; Table 1 ) and other signs/symptoms of seasonal allergic conjunctivitis had to be present bilaterally.

Patients meeting the inclusion criteria were randomly assigned to one of the two treatment groups. Patients were instructed on proper dosing technique.

The first dose of medication, one drop in each eye, was instilled at the out patient clinic. At one minute post dose, patients were queried concerning the ocular comfort of the medications. Ocular comfort was graded by each patient according to a 4-point scale of burning/ stinging (Table 2). Patients were instructed to dose the medication twice daily and return to the out patient clinic between day 5 and day 8 with the trial medication bottle.

\section{Visit (2): follow up, day 5 to day 8}

One week later (Visit 2), medical and medication history were reviewed and patients were queried regarding compliance to the dosing regimen and any adverse events since the last visit, using the same rating scale from visit 1 (Table 2). An external eye examination was performed to assess the degree of conjunctival hyperemia, eyelid swelling and mucous discharge. Itching and tearing were subjectively graded by patients. An assessment of global efficacy relative to baseline was performed by both the investigator and patient (Table 3).

Patients were instructed to return to the out patient clinic in approximately two weeks.

\section{Visit (3): follow up/ termination visit, day 21 to 24}

Two weeks later (visit 3), medical and medication history were reviewed and patients were again queried regarding compliance to dosing regimen and any adverse events since the last visit. Patients rated their overall ocular comfort since the last visit, using the same rating scale from visit 1 (Table 2 ).

Another external eye examination was performed to assess the degree of the conjunctival hyperemia, eyelid swelling and mucous discharge. Itching and tearing were subjectively graded by the patients. An assessment of global efficacy relative to baseline was performed by both the investigator and patient (Table 3).

\section{Efficacy Assessments Primary efficacy variable}

The primary efficacy variable was the responder rate at visit 2 (day 5 to 8 ) as judged by the patients. Patients were asked to assess the treatment in terms of relief of symptoms relative to baseline (pretreatment, visit 1) using a 5-point grading scale (table 3, Patient Global Efficacy).

A score of 0 or 1 (excellent or good efficacy, i.e., complete or distinct relief) was used to define a responder.

\section{Secondary efficacy variables}

Secondary efficacy variables, measured at follow-up visits, included individual scores for signs (hyperemia, chemosis, eyelid swelling and mucous discharge) and symptoms (itching and tearing), patient and investigator assessment of global efficacy relative to baseline condition (Table 3 ) and responder rate (patient assessment at visit 3 and investigator assessment at visits 2 and 3 ). 
Table (1): Scoring of ocular signs and symptoms.

\begin{tabular}{|c|c|}
\hline Score & Signs and symptoms \\
\hline \multicolumn{2}{|c|}{ Conjunctival hyperemia (0.5 increments allowed) } \\
\hline 0 & Absent (vessels normal) \\
\hline 1 & Mild (some vessels definitely injected above normal) \\
\hline 2 & Moderate (diffusely red eye with individual vessels dilated but not still discernable) \\
\hline 3 & Severe (intensely red eye with intensive dilatation of conjunctival vessels) \\
\hline \multicolumn{2}{|c|}{ Conjunctival chemosis ( 0.5 increments allowed) } \\
\hline 0 & Absent or visually not detectable \\
\hline 1 & Visually evident ,raised conjunctiva at limbal area \\
\hline 2 & Ballooning of the conjunctiva \\
\hline \multicolumn{2}{|c|}{ Eyelid swelling (0.5 increments allowed) } \\
\hline 0 & Absent \\
\hline 1 & Mild (lids are little puffy) \\
\hline 2 & Moderate (frank swelling of upper and lower lids) \\
\hline 3 & Severe (eyelids are swollen shut) \\
\hline \multicolumn{2}{|c|}{ Mucous discharge } \\
\hline 1 & Absent \\
\hline 2 & Present \\
\hline \multicolumn{2}{|c|}{ Itching (0.5 increments allowed) } \\
\hline 0 & Absent \\
\hline 1 & An intermittent tickle sensation involving more than just the inner corner of eye \\
\hline 2 & Mild continuous itch (can be localized) not requiring rubbing \\
\hline 3 & A definite itch, you would like to rub the eye \\
\hline 4 & An incapacitating itch which would require significant eye rubbing \\
\hline \multicolumn{2}{|c|}{ Tearing (0.5 increments allowed) } \\
\hline 0 & Absent \\
\hline 1 & Mild (eye feels slightly watery) \\
\hline 2 & Moderate (occasional need to wipe the eye) \\
\hline 3 & Severe (tears rolling down cheeks) \\
\hline
\end{tabular}

Table (2): Patient assessment of ocular comfort/tolerability.

\begin{tabular}{|c|l|}
\hline Grade & $\begin{array}{l}\text { Assessment of ocular comfort/tolerability } \\
(0.5 \text { increments allowed) }\end{array}$ \\
\hline 0 & None \\
\hline 1 & $\begin{array}{l}\text { Mild (Slightly perceptible burning/ } \\
\text { stinging sensation) }\end{array}$ \\
\hline 2 & $\begin{array}{l}\text { Moderate (uncomfortable burning/ } \\
\text { stinging sensation) }\end{array}$ \\
\hline 3 & $\begin{array}{l}\text { Severe (intense burning/stinging } \\
\text { sensation) }\end{array}$ \\
\hline 4 & $\begin{array}{l}\text { Very severe (extremely intense burning/ } \\
\text { stinging sensation) }\end{array}$ \\
\hline
\end{tabular}

Tolerability and safety assessments

Ocular comfort was assessed by patients one minute after drops were instilled at visit 1 and as overall comfort since the previous visit at visit 2 and 3 using the 5-point standardized rating scale of burning/stinging sensation (Table 2).

The primary safety variable was the frequency of ocular and non-ocular adverse events, reported at visit two and three.

Adverse events were recorded throughout the study. Adverse events were defined as any clinically relevant worsening from patient's baseline examination. 
Table (3): Global efficacy ratings.

\begin{tabular}{|l|l|l|}
\hline \multicolumn{2}{|l|}{ Rating } & \multicolumn{1}{c|}{ Description } \\
\hline \multicolumn{2}{|l|}{ Patient assessment of global efficacy } \\
\hline 0 & Excellent & $\begin{array}{l}\text { Complete or almost complete } \\
\text { relief of ocular allergy } \\
\text { symptoms. }\end{array}$ \\
\hline 1 & Good & $\begin{array}{l}\text { Distinct relief of ocular allergy } \\
\text { symptoms. }\end{array}$ \\
\hline 2 & Fair & $\begin{array}{l}\text { Some relief of ocular allergy } \\
\text { symptoms. }\end{array}$ \\
\hline 3 & Poor & $\begin{array}{l}\text { No relief of ocular allergy } \\
\text { symptoms. }\end{array}$ \\
\hline 4 & Deterioration & Worsening of symptoms \\
\hline Doctor assessment of global efficacy \\
\hline 0 & Excellent & $\begin{array}{l}\text { Complete or almost complete } \\
\text { relief of sign and symptoms of } \\
\text { SAC. }\end{array}$ \\
\hline 1 & Good & $\begin{array}{l}\text { Distinct relief of sign and } \\
\text { symptoms of SAC. }\end{array}$ \\
\hline 2 & Fair & $\begin{array}{l}\text { Some relief of sign and } \\
\text { symptoms of SAC. }\end{array}$ \\
\hline 3 & Poor & No relief \\
\hline 4 & Deterioration & Worsening of symptoms. \\
\hline
\end{tabular}

\section{Statistical analysis}

Responder rate and ratings for global efficacy, signs, symptoms and comfort were compared between treatment groups with analysis of variance.

All tests were two sided and considered statistically significant if the corresponding $\mathrm{P}$ value was less than or equal to 0.05 .

For validity, right and left eye measurements were examined separately, anticipating that the outcomes would be similar. The number and percentage of adverse events were summarized for all reported events, serious events and discontinuation due to adverse events.

\section{Results}

Of 66 subjects who were screened, all (100\%) were qualified and randomized to treatment with either $(\mathrm{OH}) \mathrm{N}=32$ or $(\mathrm{L}) \mathrm{N}=34$ and were evaluated for efficacy and safety. All patients $\mathrm{N}=32$ in $(\mathrm{OH})$ group completed the trial, and 31 of 34 patients in (L) completed the trial. One patient in (L) group was discontinued at visit 1 due to significant discomfort (burning and stinging) and two additional patients in the (L) group were lost to follow up at visit 3.

\section{Baseline characteristics}

No statistical differences in demographics or baseline characteristics were found between the two treatment groups (Table 4). The average age of patients was 36.2 years. Approximately $75 \%$ of the patients in each group were women, and the majorities (93.3\%) were Caucasian.

No differences were noted between treatment groups in concomitant therapy based on initial or follow-up medical histories.

\section{Efficacy evaluation \\ Responder rate}

At the first follow-up visit (day 5 to 8), there were more responders (patient with excellent or good global efficacy) to Olopatadine hydrochloride than to Lodoxamide based on both patient (72\% vs.54\%) and investigator (88\% vs.55\%) assessment. The difference between the treatments was statistically significant for the investigator assessment $(P<0.0001)$.

At the second follow-up visit (day 21 to 24), the responder rate was significantly higher for $\mathrm{OH}$-treated patients than for L-treated patients for both patients ( $91 \%$ vs. $55 \% ; \mathrm{P}=0.0001)$ and investigator assessments (94\% vs. $42 \%$; $\mathrm{P}<0.0001$ ) (Table 2).

\section{Global efficacy}

Olopatadine treatment was found to be statistically superior to Lodoxamide in relieving the signs and symptoms of allergic conjunctivitis by both patient and investigator at each follow up visit (Table 5). For each treatment group, the mean global efficacy scores were compared between visit two (day 5) and visit three (day 21) to examine the efficacy of each treatment over the duration of the trial. Within the treatment groups, no statistically significant differences were found between the visits, although $\mathrm{OH}$-treated patients showed a numerical improvement from visit two to visit three and Lodoxamide treated patients did not. 
Table (4): Baseline characteristics.

\begin{tabular}{|c|c|c|}
\hline Variable & $\begin{array}{c}\text { Olopatadine } \\
\text { hydrochloride } \\
(n=32)\end{array}$ & $\begin{array}{l}\text { Lodoxamide } \\
\qquad(n=34)\end{array}$ \\
\hline $\begin{array}{ll}\text { Sex: } & \\
& \text { Female } \\
\text { Male }\end{array}$ & $\begin{array}{c}24(75 \%) \\
8(25 \%)\end{array}$ & $\begin{array}{l}25(73.5 \%) \\
9(26.5 \%)\end{array}$ \\
\hline $\begin{array}{l}\text { Age (years) } \\
\text { (mean } \pm \text { SD) }\end{array}$ & $37.47 \pm 16.8$ & $35.2 \pm 14.4$ \\
\hline $\begin{array}{l}\text { Race: } \\
\text { Caucasian } \\
\text { Others }\end{array}$ & $\begin{array}{c}28(87.5 \%) \\
4(12.5 \%)\end{array}$ & $\begin{array}{c}34(100 \%) \\
0(0 \%)\end{array}$ \\
\hline $\begin{array}{l}\text { History of ocular } \\
\text { allergy: } \\
\text { Yes } \\
\text { No }\end{array}$ & $\begin{array}{c}8(25 \%) \\
24(75 \%)\end{array}$ & $\begin{array}{c}6(17.7 \%) \\
28(82.3 \%)\end{array}$ \\
\hline
\end{tabular}

Table (5): Mean global efficacy based on patient and doctor response.

\begin{tabular}{|l|c|c|c|c|}
\hline & & \multicolumn{3}{|c|}{ Mean global efficacy } \\
\hline Response & Day & $\begin{array}{c}\text { Olopatadine } \\
\text { hydrochloride }\end{array}$ & Lodoxamide & $P$-value \\
\hline Patient & 5 & 0.91 & 1.36 & 0.03 \\
\hline & 21 & 0.72 & 1.49 & 0.0005 \\
\hline Doctor & 5 & 0.66 & 1.36 & 0.001 \\
\hline & 21 & 0.56 & 0.53 & $<0.0001$ \\
\hline
\end{tabular}

\section{Ocular signs and symptoms}

Individual sign and symptom scores were compared between the treatment groups at baseline and at the two follow-up visits. The ocular signs of conjunctival chemosis, eyelid swelling and mucous discharge were absent in the majority of patients (only two patients presented with conjunctival chemosis, one patient with eyelid swelling and one patient with mucous discharge). For this reason, conjunctival chemosis, eyelid swelling and mucous discharge were not compared as individual signs but were included in the total scores. The major ocular allergy manifestation was ocular itching. No significant differences were found between the treatments for individual or total sign and symptom scores at baseline. At both follow-up visits, Olopatadine treated patients had significantly lower scores for conjunctival hyperemia and itching. No differences were observed between treatments for tearing.

Changes in the individual and total scores were compared between study visits for each treatment group to examine the efficacy of each treatment over the duration of the trial. Conjunctival hyperemia, itching and tearing along with total signs and symptoms, were significantly reduced in the $\mathrm{OH}$-treated group between the baseline visit and visit two (day 5 to 8). Itching, tearing and total symptom scores were significantly reduced in the L-treated group between the baseline visit and visit two (day 5-8). Between day five and day $21, \mathrm{OH}$ maintained or further reduced the conjunctival hyperemia, itching and tearing, as well as the total signs and symptoms scores, although the differences between day five and day 21 were not significant. Between day five and day 21 was a slight but not significant loss of efficacy for all outcome variables with the exception of tearing score in the Lodoxamide treated group.

\section{Ocular comfort}

Ocular comfort was assessed by the patients at visit one after the first dose and at visit two and three regarding the overall ocular comfort since the previous visit. At all visits, $\mathrm{OH}$ and $\mathrm{L}$ were rated between zero (comfortable-no sensation) to one (mild-slightly perceptible sensation). No significant differences were found between treatments.

\section{Safety}

One serious treatment-related adverse event occurred during the study. One patient in the L-group experienced severe discomfort (burning and stinging) in the eyes upon drop instillation at visit one and asked to be discounted from the trial. Other adverse events were mild to moderate in severity. The most common ocular adverse events were burning and stinging, which were reported by two patients in the Olopatadine group and three patients in the Lodoxamide group. Headache was the most common systemic adverse event and was reported by one Olopatadine-treated patient and two Lodoxamide-treated patients.

\section{Discussion}

In this three week study, the efficacy of $(\mathrm{OH})$ in relieving and controlling the signs and symptoms of seasonal allergic conjunctivitis was shown to be superior to that of $(\mathrm{L})$. Measurements of responder rate and global efficacy, assessment by both the patient and 
investigator, were significantly higher for Olopatadine than Lodoxamide. Individual sign and symptom scores supported the responder rate and global efficacy assessments and demonstrated that Olopatadine reduced and maintained ocular signs and symptoms to greater extent than Lodoxamide. No significant differences in ocular comfort and tolerability, assessed after instillation of first drop of medication and over the duration of the trial, were found between the two treatment groups. Safety, as measured by adverse events, was also similar between the treatment groups.

Allergy patients seek help because their allergic signs and symptoms impair their quality of life ${ }^{(5)}$. Topical treatments for ocular allergies offer multiple therapeutic advantages over systemic products, including a more rapid onset of action (within three minutes) and minimal adverse systemic effects ${ }^{(6,7)}$.

Newer dual-acting ${ }^{(7,8,9)}$ and multiple-acting agents ${ }^{(10)}$ have pharmacological actions that include an antihistaminic effect to provide immediate relief and additional effects to act on the mediators of the late-phase reaction. The greater efficacy of Olopatadine in treating seasonal allergic conjunctivitis demonstrated in this trial may be the result of its multiple and distinct modes of action on allergic cascade. Olopatadine has been shown to block both $\mathrm{H}_{1}$ and $\mathrm{H}_{2}$ receptors more effectively than Lodoxamide. ${ }^{(8,9)}$

The recommended dose of $(\mathrm{OH})$ is one drop b.i.d. in the affected eye(s) every 8-12 hours and the recommended dose of ( $L$ ) is one drop in each affected eye two times per day at an interval of 6-8 hours ${ }^{(11,12)}$.

The Berdy study ${ }^{(4)}$ utilized the conjunctival allergen challenge (CAC) model, whereas the current study utilized an environmental model. The CAC model is the gold standard for evaluating various aspects of the ocular immune response and the inhibitory effects of drugs; however, this model does not provide information on drug efficacy or tolerability with long-term use. The current study utilized an environmental analysis and was intended to compare the two agents in a real-life actual clinical setting with true environmental allergen exposure during a typical allergy season. In the current three week environmental study during allergy season, comparison of the efficacy of the drugs under actual patient use found Olopatadine to have superior efficacy over Lodoxamide. Additionally, during the three week treatment with these medications, no differences in comfort or tolerability were found between Olopatadine and Lodoxamide.

Two other studies compared topical preparation of ketotifin and Olopatadine for the treatment of allergic conjunctivitis. These studies, Aguilar (2000) and Artal et al (2000), examined a different formulation of ketotifin $0.025 \%{ }^{(11)}$, which is not currently marketed in Mosul city, and is not considered relevant to the current study.

\section{Conclusion}

In a three weeks study under actual patient use conditions during spring allergy season, Olopatadine ophthalmic solution $0.1 \%$ was found to be superior to Lodoxamide ophthalmic solution $0.1 \%$ in relieving the signs and symptoms of allergic conjunctivitis.

No differences in comfort, tolerability, or safety were noted between treatment groups over the course of the study.

The superior efficacy and sustained inhibition of allergic response make Olopatadine an ideal treatment option for allergic conjunctivitis.

\section{References}

1. Bielory L. Allergic \& immunologic disorders of the eye. Part 2: Ocular Allergy. J Allergy Clin. Immunology 2000; 106: 1019-1032.

2. Artal MN, Luna JD, Discepola MA. Forced choice comfort study of olopatadine hydrochloride Acta Ophthalmol Scand. 2000; 78: 64-65.

3. Package insert for patanol. In: physician s Desk Reference for ophthalmic medicine $30^{\text {th }}$ edition Montvale: medical Economics, Co. 2001: 216-217.

4. Berdy GJ, Spangler DL, Bensch G, Berdy SS, Brusatti RC. A compairison of relative efficacy \& clinical performance of olopatadine hydrochloride $\quad 0.1 \%$ ophthalmic solution \& ketotifin fumerate $0.025 \%$ ophthalmic solution in the conjunctival challenge model clin ther: 2000; 22: 826-833. 
5. Abelson MB. Evaluation of olopatadine, a new ophthalmic anti-allergic agent with dual activity, using the conjunctival challenge model.Ann Allergy Asthma Immunol 2003; 81:211-218.

6. Yanni JM, Stepjens DJ,Miller ST,et al. the in vitro \& in vivo ocular pharmacology of olopatadine (AL-4943A), an effective antiallergic/anti-histamine agents. J Ocular Pharmaco/ Ther. 2001; 12(4): 389-400.

7. Buckley RJ. Allergic eye disease; a clinical challenge. Clin Exp Allergy. 1998; 28 (6):39-43.

8. Mc Gill JI, Holgate ST, Church MK, Bacon A. Allergic eye disease mechanisms. Br. J Ophthalmol. 2002; 82: 1203-1214.

9. Abelson $\mathrm{MB}$, Udell $\mathrm{IJ} . \mathrm{H} 2$ receptors in human ocular surface. Arch Ophthalmol. 2000; 99:302-303.
10. Friedlaender $\mathrm{MH}$. A review of causes \& treatment of bacterial \& allergic conjunctivitis, clin. Ther. 2000; 17: 800809.

11. Aquilar, A.J. Comparative study of clinical efficacy \& tolerance in seasonal allergic conjunctivitis management with $0.1 \%$ olopatadine hydrochloride versus $0.05 \%$ ketotifin fumerate. Acta Ophthalmol Scand. 2000; 78:52-55.

12. Abelson MB. Conjunctival allergen challenge. A clinical approach to studying allergic conjunctivitis. Arch Ophthalmol. 2000; 108: 84-88. 